\title{
Residents' Willingness to Maintain Contracts with Family Doctors: a Cross-sectional Study in China
}

\author{
Chao Wang, Ph. $D^{7}$, Shijiao Yan, Ph. $D^{2}$, Heng Jiang, Ph. $D^{3,4}$, Zhiqiang Nie, Ph. $D^{7}$, \\ Mia Miller, Ph. $D^{3}$, Yan He, Ph. $D^{5}$, Yingying Guo, M.M' ${ }^{6}$, Yong Gan, Ph. $D^{7}$, \\ Qingfeng Tian, Ph. $D^{5}$, Chuanzhu LV, M.D.8, and Zuxun Lu, Ph. $D^{7}$ (1)
}

\begin{abstract}
'Department of Social Medicine and Health Management, School of Public Health, Tongji Medical College, Huazhong University of Science and Technology, Wuhan, Hubei, China; ${ }^{2}$ School of Public Health, Hainan Medical University, Haikou, Hainan, China; ${ }^{3}$ Centre for Alcohol Policy Research, School of Psychology and Public Health, La Trobe University, Melbourne, VIC, Australia; ${ }^{4}$ Centre for Health Equity, Melbourne School of Population and Global Health, University of Melbourne, Melbourne, VIC, Australia; '5epartment of Social Medicine and Health Management, School of Public Health, Zhengzhou University, Zhengzhou, Henan, China; ${ }^{6}$ Children's Healthcare Department, Tongji Hospital, Tongji Medical College, Huazhong University of Science and Technology, Wuhan, Hubei, China; ${ }^{7}$ Department of Emergency, The Second Affiliated Hospital of Hainan Medical University, Haikou, Hainan, China; ${ }^{8}$ Emergency and Trauma College, Hainan Medical University, Haikou, Hainan, China.
\end{abstract}

BACKGROUND: Most previous studies of the family doctor contract services (FDCS) evaluated its quality by using residents' signing rates, awareness, and satisfaction. We hypothesize that renewal willingness could be another important indicator to examine the quality of FDCS.

OBJECTIVE: To measure residents' willingness to maintain contracts with family doctors and examine the influencing factors.

DESIGN: Cross-sectional study.

PARTICIPANTS: 11,250 residents in 31 provincial administrative regions across China.

MAIN METHODS: A multistage stratified random sampling method was used to recruit participants. Univariate analysis, mixed-effect regression model analysis, and stepwise multivariate logistic regression analysis were performed to determine the influencing factors of residents' willingness to maintain contracts with family doctors.

KEY RESULTS: About $71.3 \%$ participants who contracted with and received healthcare services from family doctors were willing to maintain contracts with family doctors in China. Residents registering as local households (OR $=1.192,95 \% \mathrm{CI}=1.039-1.368)$, enrolled in medical insurance $(O R=1.299,95 \% \mathrm{CI}=1.011-1.668)$, reporting better health $(\mathrm{OR}=1.246,95 \% \mathrm{CI}=1.100$ 1.413), with shorter walking time to the nearest healthcare center (compared with > 30 min walking time, $<15$ min: $O R=1.209,95 \%$ CI $=1.003-1.458 ; 15-30 \mathrm{~min}$ : $\mathrm{OR}=1.288,95 \% \mathrm{CI}=1.124-1.475)$, and trusting in $(\mathrm{OR}=$ 4.403, 95\% CI = 3.849-5.036) and satisfied with $(\mathrm{OR}=$ $18.514,95 \% \mathrm{CI}=16.195-21.165)$ their family doctors had significantly higher willingness to maintain contracts with family doctors.

CONCLUSIONS: Residents' willingness to maintain contracts with family doctors could be another evaluation

Prior presentations: None.

Supplementary Information The online version of this article (https:// doi.org/10.1007/s11606-020-06306-y) contains supplementary material, which is available to authorized users.

Received March 8, 2020

Accepted October 7, 2020

Published online November 2, 2020 indicator of the quality of FDCS in China. Improving the accessibility and quality of healthcare services from family doctors may increase residents' willingness to keep contracts with family doctors and promote the implementation of FDCS.

KEY WORDS: renewal willingness; family practice; family doctor contract service; influencing factors; Chinese.

J Gen Intern Med 36(3):622-31

DOI: $10.1007 / \mathrm{s} 11606-020-06306-y$

(c) Society of General Internal Medicine 2020

\section{INTRODUCTION}

The family doctor contract service (FDCS) is considered a core component of primary health care in China. The key aim of the FDCS is to provide the public with a proactive, consistent, comprehensive, and affordable health accountability management model by establishing stable connections between community residents and family doctors. ${ }^{1}$

The FDCS was launched in China in 2009 as an innovative and fundamental policy in New Medical Reform, and was officially implemented nationwide since 2016. Under the unified policy issued by the central Government, different areas of China have explored and established different practice models, such as the "1 (family doctor) +1 (district hospital) + 1 (municipal hospital)" model in Shanghai, the "Co-management of Doctors of Three Kinds" model in Xiamen, and the "Medication-Rehabilitation-Nursing Combined Service" model in Hangzhou. ${ }^{2}$ In addition to all healthcare services offered to the general population, residents who contract with family doctors can receive more healthcare services from their family doctors, such as regular health follow-ups, home inpatient services, and the green channel in bidirectional referral. ${ }^{3} \mathrm{Up}$ until November 2017, more than $95 \%$ of cities in China had launched FDCS, with population coverage exceeding $35 \% .^{4}$ 
It is voluntary and free for residents to sign with family doctors in China, with a contract period lasting 1 year. After the contract period expires, residents can renew contracts with their family doctors, choose another family doctor to sign up with, or cease the contract. ${ }^{5}$ Even though the mandatory FDCS was performed in European and American countries, there was generally more than one healthcare center for residents to choose and sign up. ${ }^{6,7}$ In this case, the number of residents who hold contracts with family doctors is directly linked to their income and career development. To some extent, this could objectively reflect family doctors' healthcare qualities and diagnosis or treatment levels. ${ }^{8}$

The FDCS facilitates patient-centered healthcare services, so residents and patients can provide the most authentic evaluations of FDCS based on their own experiences. However, most of the existing studies on FDCS focused on examining residents' awareness of the FDCS, or their trust in and satisfaction with family physicians. ${ }^{9-11}$ Nevertheless, studies have shown there were limitations in these evaluation indexes in terms of their comprehensiveness, pertinence, and practice guidance. ${ }^{12}$ In comparison, residents' willingness to maintain contracts with their family doctors could be a more insightful measure and has universal public health significance, which would shed new light on establishing and adjusting health policies relevant to family doctors for both China and Western countries.

To date, there have been few studies on residents' willingness to renew contracts with family doctors and the influencing factors. In this study, we seek to address this gap by evaluating residents' willingness to maintain contracts with family doctors and identifying the influencing factors, with the aim of providing evidence-based recommendations for the further development of FDCS.

\section{METHODS}

\section{Study Design and Settings}

A cross-sectional survey was designed and conducted in 31 provincial administrative regions across China from March to April 2019 (Appendix Fig. 1). Using a multistage stratified random sampling method, we selected a number of primary health institutions (community health centers or township health centers) in proportion to the local population size and the total number of districts/counties from each province. Under the cooperation of the national and provincial Community Health Associations, we, with the help of primary health institutions, sent the electronic questionnaire accessible to cellphones and computers to each research unit by E-mail.

\section{Sample and data collection}

There was no restriction on participants' inclusion if they were able to complete the questionnaire independently. Residents with reading problems or hospital-diagnosed psychiatric disorders were excluded. Only one member of a family in contract with a family doctor (generally the main income earner or the main service user) was recruited in this study. The questionnaire applied in the survey mainly covered the following contents: residents' demographic characteristics, accessibility to healthcare services, and evaluations of their willingness to maintain contracts with family doctors.

Patients voluntarily participated in the study. Before filling out the questionnaire, all participants provided informed consent on the first page of the questionnaire. Participants' information was completely confidential and recorded anonymously. This study was approved by the ethics committee of Tongji Medical College institutional review board, Huazhong University of Science and Technology, Wuhan, China.

\section{Data Analysis}

Data from the survey were gathered on a computer, then inputted into SPSS software (Version 22.0, SPSS Inc., Chicago, IL, USA) for further analyses. We dichotomized the answers to the question of patients' willingness as "willing" and "unwilling." We used ArcGIS software (Version 10.2, Environmental System Research Institute, Redlands, CA, USA) to present participants' geographical distribution. The descriptive statistics were presented as the number of observations with percentage (\%), and we analyzed the difference in demographic statistics by Chi-square $\left(\chi^{2}\right)$ test. Due to the disparities in socioeconomic status between the urban and rural participants, and those in different regions, the data have a typical hierarchical structure. We performed a mixed-effect logistic regression model with a random cluster effect (geographic regions and resident areas (urban or rural)) to investigate the adjusted OR $(95 \% \mathrm{CI})$ of influencing factors of residents' willingness to renew the FDCS. The data aggregation was assessed using the estimated intraclass correlation coefficient (ICC). Further, we explored the factors influencing participants' willingness to maintain contracts for residents in Eastern, Central, and Western China, respectively (Appendix Fig. 2), through stepwise multivariable logistic regression analysis (level for selection: $P=0.05$, and level for elimination: $P=0.10$ ). The significance level was accepted as $P<0.05$ (two-sided).

\section{RESULTS}

A total of 171,230 residents were randomly recruited in the survey. As contracting with a family doctor was the prerequisite for renewing a contract, only 11,610 residents who contracted with and received healthcare services from family doctors were suitable for this study. We further excluded 336 interviewees aged $<18$ years and 24 questionnaires with logical errors. A total of 11,250 (96.9\%) eligible questionnaires were included for final analysis (Fig. 1).

The mean age of the participants was 32.93 (standard deviation: 14.03 ) years old and $47.0 \%$ were female. Of them, $8016(71.3 \%)$ who contracted with and received healthcare 


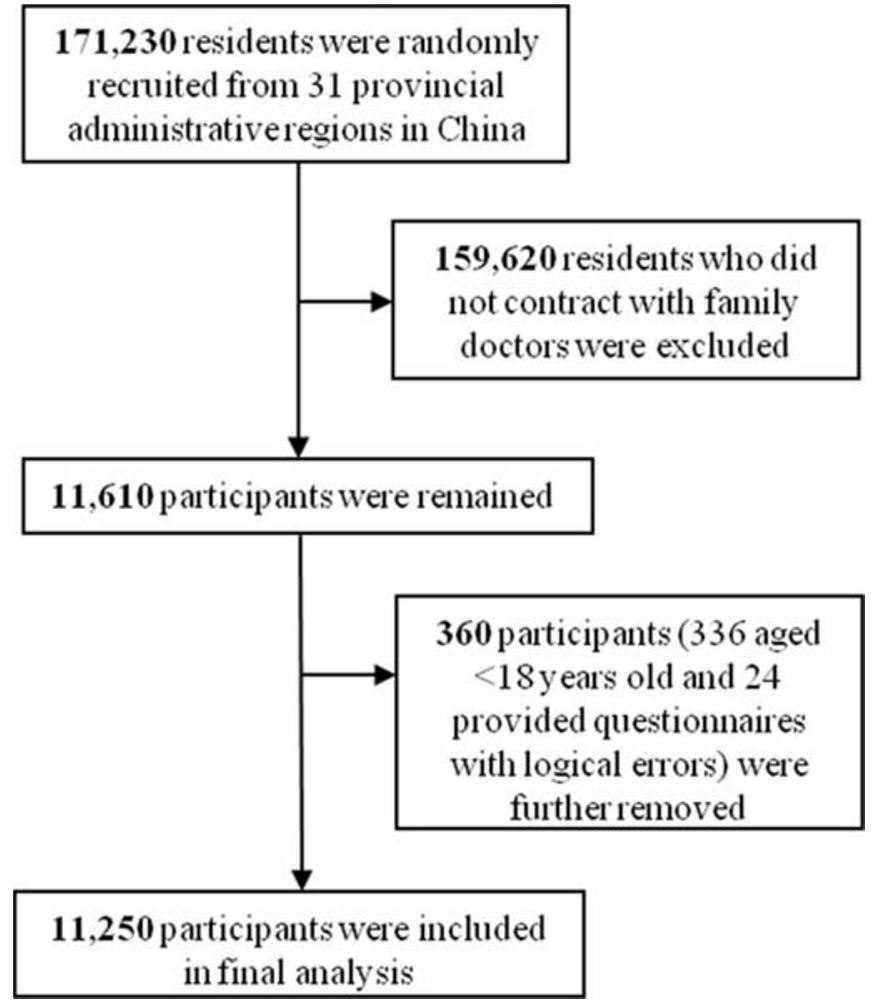

Figure 1 The flow chart for the sampling in this study: 31 provincial administrative regions, China, March to April 2019.

services from family doctors were willing to maintain contracts. Results of the univariate analysis suggested the male participants and residents aged 45 years and older, from Eastern and Central China, living in urban areas, registered as local households, being of higher socioeconomic status, unemployed, enrolled in medical insurance, reporting better health statuses, without chronic diseases, being sick in last 2 weeks, without alcohol consumption, exercising regularly, living near to healthcare centers, trusting in their family doctors, and satisfied with their family doctors had significantly higher willingness to maintain contracts with family doctors $(P<0.05)$ (Table 1). Considering the significant differences in the willingness to maintain contracts of residents from different geographic regions, we conducted univariate analyses with participants from Eastern, Central, and Western China, respectively. The results showed that gender, rural/urban location, household registration status, socioeconomic status, self-rated health status, illness within the last 2 weeks, walking time to nearest healthcare center, trust in family doctor or not, and satisfaction with family doctor or not were influencing factors for residents from Eastern, Central, and Western China. Besides, age, chronic disease status, and alcohol consumption were also other influencing factors for residents from Eastern and Central China. Further, having medical insurance and participating in physical exercise were other influencing factors for residents from Eastern China (Table 2).

In the mixed-effect logistic regression analysis, ICCs range from 4 to $12 \%$. Residents registered as local households $(\mathrm{OR}=1.192,95 \% \mathrm{CI}=1.039-1.368)$, enrolled in medical insurance $(\mathrm{OR}=1.299,95 \% \mathrm{CI}=1.011-1.668)$, reporting better health statuses $(\mathrm{OR}=1.246,95 \% \mathrm{CI}=$ 1.100-1.413), with shorter walking time to the nearest healthcare center $(<15 \mathrm{~min}: \mathrm{OR}=1.209,95 \% \mathrm{CI}=1.003-$ 1.458; 15-30 min: $\mathrm{OR}=1.288,95 \% \mathrm{CI}=1.124-1.475)$, trusting in family doctors $(\mathrm{OR}=4.403,95 \% \mathrm{CI}=3.849$ $5.036)$, and satisfied with family doctors $(\mathrm{OR}=18.514$, 95\% CI $=16.195-21.165$ ) had significantly higher willingness to maintain contracts with family doctors (Table 3 ). In addition, we stratified the study sample by regions and conducted multivariate logistic regression analyses. The results showed that for residents from Eastern, Central, and Western China, trust in and being satisfied with family doctors were factors associated with an increased willingness to maintain contracts. Except for those factors, < $30 \mathrm{~min}$ (both $<15 \mathrm{~min}$ and $15-30 \mathrm{~min}$ ) walking time to the nearest healthcare center could be another factor promoting the maintenance of contracts with family doctors for residents from Eastern and Central China. For residents in Eastern China, living in urban areas, registered as local households, enrolled in medical insurances, and reporting better health statuses were also associated with higher willingness to maintain contracts (Table 4).

\section{DISCUSSION}

In this study, approximate $71.3 \%$ residents who contracted with and received healthcare services from family doctors 
Table 1 Univariate Analysis of the Differences of Residents' Willingness to Maintain Contracts with Family Doctors: 31 Provincial Administrative Regions, China, March to April 2019

\begin{tabular}{|c|c|c|c|c|c|c|}
\hline Variables & Characteristics & $N(\%)$ & Willing (\%) & Unwilling (\%) & $\chi^{2}$ & $P$ \\
\hline Total & & $11,250(100)$ & $8016(71.3)$ & $3234(28.7)$ & \multirow{4}{*}{32.685} & \multirow{4}{*}{$<0.001$} \\
\hline \multirow[t]{3}{*}{ Age (years old) } & $18-44$ & $8645(76.8)$ & $6050(70.0)$ & $2595(30.0)$ & & \\
\hline & $45-64$ & $2324(20.7)$ & $1741(74.9)$ & $583(25.1)$ & & \\
\hline & $\geq 65$ & $281(2.5)$ & $225(80.1)$ & $56(19.9)$ & & \\
\hline \multirow[t]{2}{*}{ Gender } & Male & $5961(53.0)$ & $4445(74.6)$ & $1516(25.4)$ & \multirow[t]{2}{*}{68.013} & \multirow{2}{*}{$<0.001$} \\
\hline & Female & $5289(47.0)$ & $3571(67.5)$ & $1718(32.5)$ & & \\
\hline \multirow[t]{3}{*}{ Geographical region } & Eastern & $6603(58.7)$ & $4774(72.3)$ & $1829(27.7)$ & \multirow[t]{3}{*}{20.281} & \multirow[t]{3}{*}{$<0.001$} \\
\hline & Central & $2351(20.9)$ & $1693(72.0)$ & $658(28.0)$ & & \\
\hline & Western & $2296(20.4)$ & $1549(67.5)$ & $747(32.5)$ & & \\
\hline \multirow[t]{2}{*}{ Rural/urban } & Urban & $6936(61.7)$ & $5108(73.6)$ & $1828(26.4)$ & \multirow[t]{2}{*}{50.501} & \multirow[t]{2}{*}{$<0.001$} \\
\hline & Rural & $4314(38.3)$ & $2908(67.4)$ & $1406(32.6)$ & & \\
\hline \multirow{2}{*}{ Household registration status } & Local & $8420(74.8)$ & $6136(72.9)$ & $2284(27.1)$ & \multirow[t]{2}{*}{42.927} & \multirow{2}{*}{$<0.001$} \\
\hline & Immigrate & $2830(25.2)$ & $1880(66.4)$ & $950(33.6)$ & & \\
\hline \multirow[t]{4}{*}{ Educational level } & Junior high school and below & 1541 (13.7) & $1133(73.5)$ & $408(26.5)$ & \multirow[t]{4}{*}{4.964} & \multirow[t]{4}{*}{0.174} \\
\hline & High school/secondary school & 1393 (12.4) & $997(71.6)$ & $396(28.4)$ & & \\
\hline & Junior college & $2044(18.2)$ & $1441(70.5)$ & $603(29.5)$ & & \\
\hline & Bachelor degree or above & $6272(55.8)$ & 4445 (70.9) & $1827(29.1)$ & & \\
\hline \multirow[t]{2}{*}{ Economic status } & Fairly good & 9194 (81.7) & $6740(73.3)$ & $2454(26.7)$ & \multirow[t]{2}{*}{103.756} & \multirow{2}{*}{$<0.001$} \\
\hline & Disadvantaged & $2056(18.3)$ & $1276(62.1)$ & $780(37.9)$ & & \\
\hline \multirow{3}{*}{ Marital status } & Married & $4544(40.4)$ & $3289(72.4)$ & $1255(27.6)$ & \multirow{3}{*}{4.872} & 0.087 \\
\hline & Unmarried & $6429(57.1)$ & $4529(74.0)$ & 1900 (29.6) & & \\
\hline & Divorced/widow & $277(2.5)$ & $198(71.5)$ & $79(28.5)$ & & \\
\hline Employment status & Employed & $5537(49.2)$ & $3893(70.3)$ & $1644(29.7)$ & 4.749 & 0.029 \\
\hline & Unemployed & $5713(50.8)$ & $4123(72.2)$ & $1590(27.8)$ & & \\
\hline Medical insurances & Have & $10,590(94.1)$ & $7576(71.5)$ & $3014(28.5)$ & 7.201 & 0.007 \\
\hline & None & $660(5.9)$ & $440(66.7)$ & $220(33.3)$ & & \\
\hline Self-rated health status & Good & 7359 (65.4) & $5682(77.2)$ & $1677(22.8)$ & 368.769 & $<0.001$ \\
\hline & $\mathrm{Bad}$ & $3891(34.6)$ & $2334(60.0)$ & $1557(40.0)$ & & \\
\hline Chronic disease & Yes & $1498(13.3)$ & $971(64.8)$ & $527(35.2)$ & 34.921 & $<0.001$ \\
\hline & No & $9752(86.7)$ & $7045(72.2)$ & $2707(27.8)$ & & \\
\hline Sick in last 2 weeks & Yes & 4120 (36.6) & $3134(76.1)$ & $986(23.9)$ & 73.569 & $<0.001$ \\
\hline & No & $7130(63.4)$ & $4882(68.5)$ & $2248(31.5)$ & & \\
\hline Smoking & Yes & $2333(20.7)$ & $1658(71.1)$ & $675(28.9)$ & 0.050 & 0.824 \\
\hline & No & 8917 (79.3) & $6358(71.3)$ & 2559 (28.7) & & \\
\hline Alcohol consumption & Yes & 4269 (37.9) & $2940(68.9)$ & $1329(31.1)$ & 19.101 & $<0.001$ \\
\hline & No & $6981(62.1)$ & $5076(72.7)$ & $1905(27.3)$ & & \\
\hline Physical exercise & Usually & $2836(25.2)$ & $2108(74.3)$ & $728(25.7)$ & 17.524 & $<0.001$ \\
\hline & Seldom & $8414(74.8)$ & $5908(70.2)$ & $2506(29.8)$ & & \\
\hline Walking time to nearest & $<15$ & $6835(60.8)$ & $5177(75.7)$ & $1658(24.3)$ & 192.907 & $<0.001$ \\
\hline healthcare center ( $\mathrm{min})$ & $15-29$ & $3133(27.8)$ & $2078(66.3)$ & $1055(33.7)$ & & \\
\hline & $\geq 30$ & $1282(11.4)$ & $761(59.4)$ & $521(40.6)$ & & \\
\hline Trust in family doctors or not & Trust & $8030(71.4)$ & $7136(88.9)$ & $894(11.1)$ & 4249.196 & $<0.001$ \\
\hline & Distrust & $3220(28.6)$ & $880(27.3)$ & $2340(72.7)$ & & \\
\hline Satisfied with FDCS or not & Satisfied & $7751(68.9)$ & $7206(93.0)$ & $545(7.0)$ & 5737.279 & $<0.001$ \\
\hline & Unsatisfied & $3499(31.1)$ & $810(23.1)$ & $2689(76.9)$ & & \\
\hline
\end{tabular}

min, minutes; FDCS, family doctor contract service. Eastern China includes Beijing, Tianjin, Hebei, Liaoning, Shanghai, Jiangsu, Zhejiang, Fujian, Shandong, Guangdong, and Hainan; Central China includes Shanxi, Jilin, Heilongjiang, Anhui, Jiangxi, Henan, Hubei, and Hunan; Western China includes Inner Mongolia, Chongqing, Guangxi, Sichuan, Guizhou, Yunnan, Tibet, Shaanxi, Gansu, Qinghai, Ningxia, and Xinjiang

were willing to maintain contracts with family doctors. This rate was similar to that in Eastern and Central Europe, where $67.6 \%$ patients reported no reason to change their family physicians. ${ }^{13}$ Although there were considerable differences in socio-cultural backgrounds and family doctor policies between China and European and American countries, residents' willingness to maintain contracts with family doctors was similar, suggesting this indicator is reliable in assessing the quality of family doctors' healthcare services. As residents who sign up or renew contracts with family doctors are recorded in primary healthcare institutions, this data is highly accessible; it will help facilitate further studies on the role of willingness to maintain contracts in evaluating the quality of FDCS.

In this study, residents' willingness to maintain contracts with family doctors increased from $70.0 \%$ of residents aged
$18-44$ years old to $80.1 \%$ of residents aged 65 years and older. Compared with younger participants, the elderly generally have a higher risk of having a disease, which would likely motivate them to seek targeted, convenient, and continuous healthcare provided by family doctors. ${ }^{14}$ Further, policy makers usually give priority to the elderly and regard the high signing rate in the elderly population as an indicator of performance success. In this case, family doctors would strive to encourage the elderly to maintain contracts. This study suggested that urban residents had significantly higher willingness to maintain contracts than those in rural areas, which was partially supported by previous studies. ${ }^{15}$ In general, the spatial accessibility of healthcare is lower in rural areas, which increases rural residents' time spent on travel and decreases their opportunities to visit family doctors. Additionally, lower salary levels and unequal promotion systems in rural 


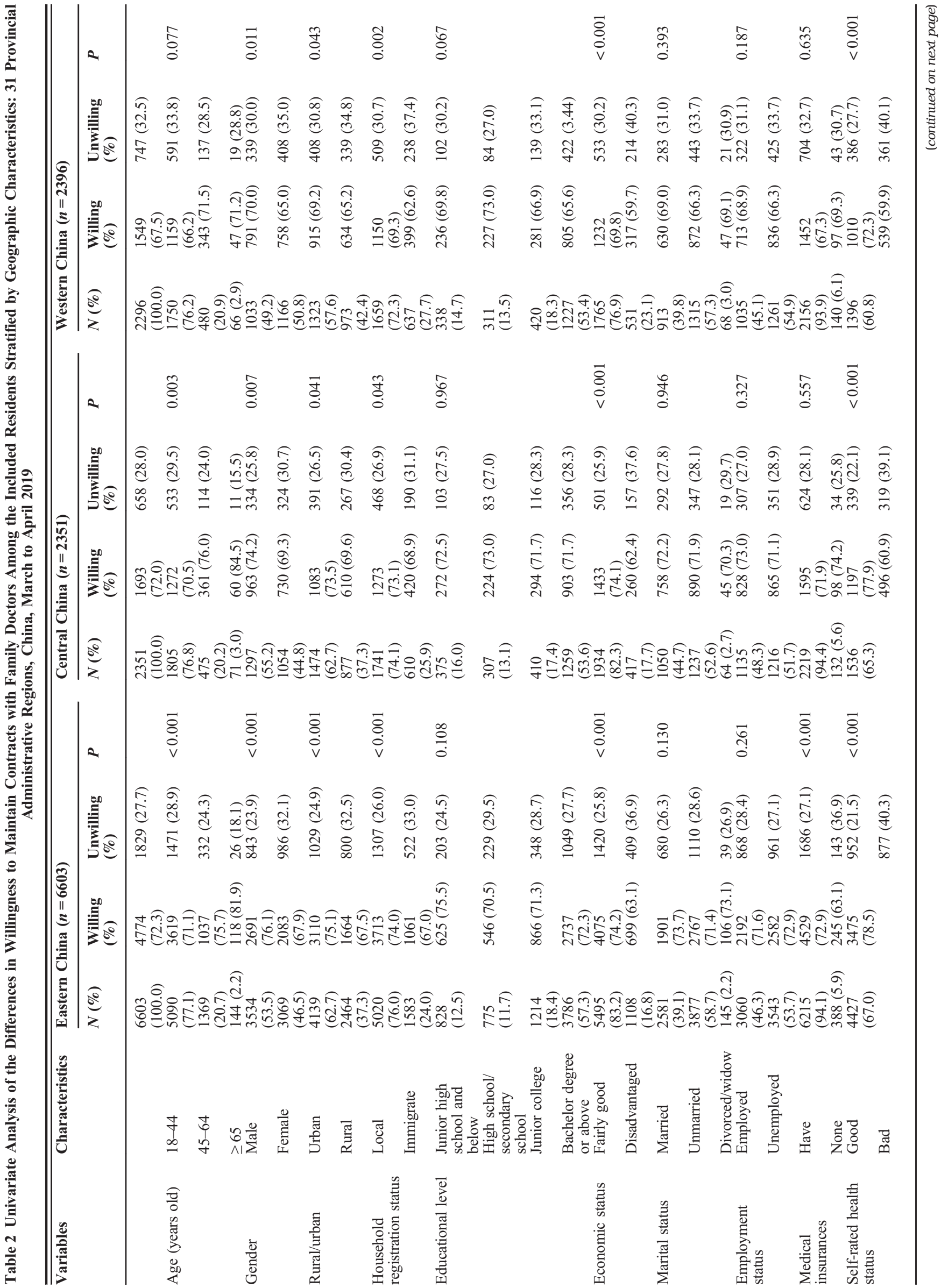




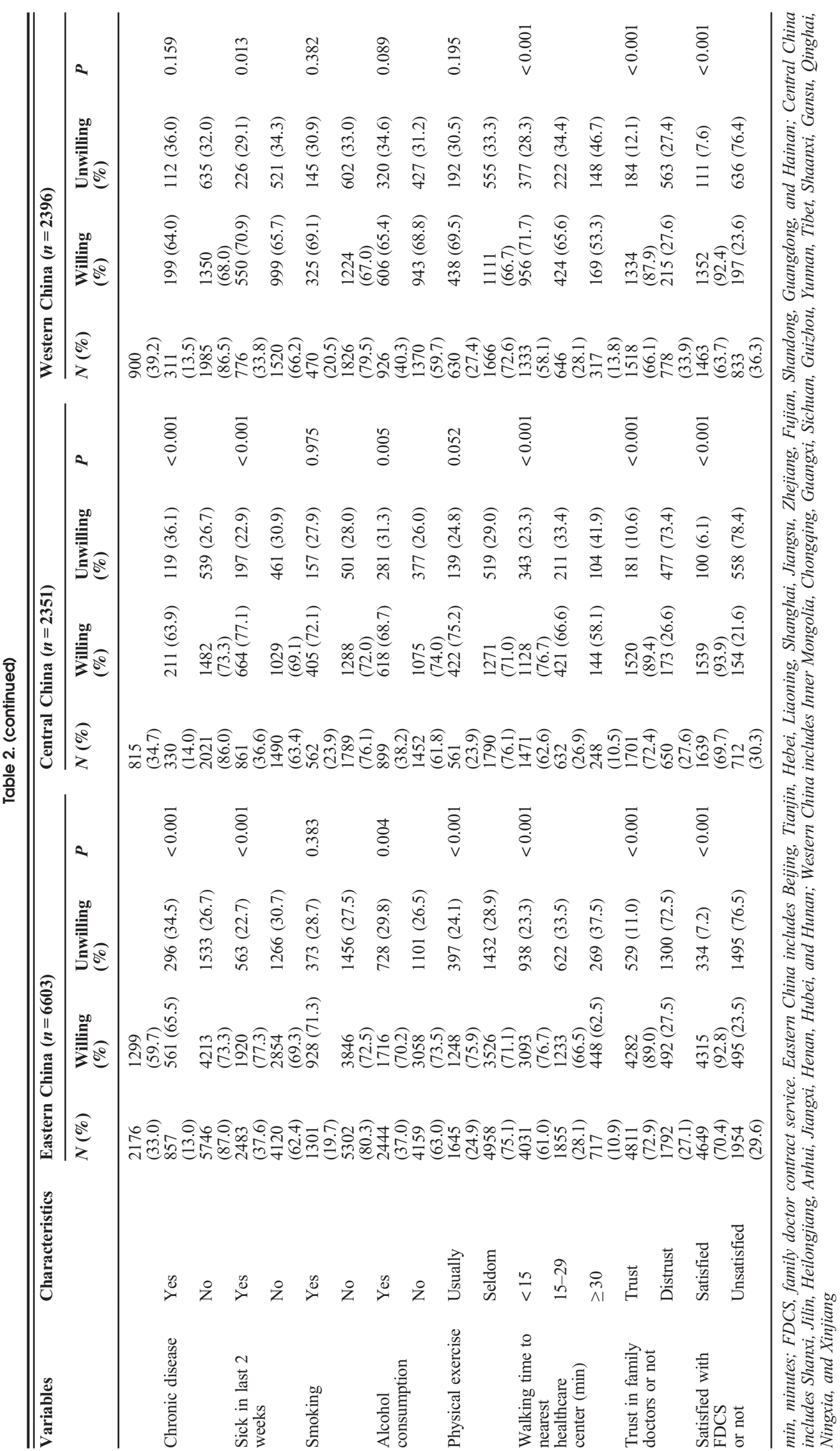


Table 3 Mixed-Effect Logistic Regression Analysis* on the Influencing Factors of Residents' Willingness to Maintain Contracts with Family Doctors: 31 Provincial Administrative Regions, China, March to April 2019

\begin{tabular}{|c|c|c|c|c|c|c|c|}
\hline Variables & Characteristics & Coefficient & S.E. & $t$ & $P$ & OR & $95 \% \mathrm{CI}$ \\
\hline Household registration (Ref.: Immigrate) & Local & 0.176 & 0.070 & 2.505 & 0.012 & 1.192 & $1.039-1.368$ \\
\hline Medical insurance (Ref.: No insurance) & Having insurance & 0.262 & 0.128 & 2.049 & 0.040 & 1.299 & $1.011-1.668$ \\
\hline Self-rated health status (Ref.: Pretty poor) & Pretty good & 0.220 & 0.064 & 3.448 & 0.001 & 1.246 & $1.100-1.413$ \\
\hline $\begin{array}{l}\text { Walking time to the nearest } \\
\text { healthcare center }(\min )(\text { Ref.: }>30)\end{array}$ & $<15$ & 0.190 & 0.954 & 1.991 & 0.046 & 1.209 & $1.003-1.458$ \\
\hline & $15-30$ & 0.253 & 0.069 & 3.652 & $<0.001$ & 1.288 & $1.124-1.475$ \\
\hline Trust family doctors or not (Ref.: Distrust) & Trust & 1.482 & 0.069 & 21.629 & $<0.001$ & 4.403 & $3.849-5.036$ \\
\hline Satisfied with FDCS or not (Ref.: Unsatisfied) & Satisfied & 2.919 & 0.068 & 42.752 & $<0.001$ & 18.514 & $16.195-21.165$ \\
\hline
\end{tabular}

Ref., reference; S.E., standard error; OR, odd ratios; CI, confidence index; LL, lower limit; UL, upper limit; min, minutes; FDCS, family doctor contract service

*Adjusted for age, gender, household registration status, economic status, employment status, medical insurances, self-rated health status, chronic disease, sick in last 2 weeks, alcohol consumption, physical exercise, walking time to nearest healthcare center, trust in family doctor or not, satisfied with family doctors or not

healthcare institutions have limited the quantity and quality of family doctors. ${ }^{16}$ In 2018, there were, on average, 3.7 licensed physicians per one thousand people in urban China comparing with 1.3 in rural areas; about $70.9 \%$ of licensed general practitioners in township healthcare centers had no bachelor's degree, while this rate was dramatically lower in urban community healthcare centers. ${ }^{17}$ This disparity may lead residents to suspect that the healthcare quality in rural areas is lower, and thus reduce their willingness to maintain contracts. The economic burden of disease may affect patients' medical experiences and decrease their willingness to maintain contracts with family doctors. ${ }^{18}$ In this study, most of the unemployed were either retired residents or students in campuses. The higher willingness to maintain contracts in the retired groups might be explained by their greater age; as for college students, they have higher awareness and compliance to FDCS, and campuses are generally equipped with highquality healthcare networks, which encourage them to maintain contracts. Being sick in the last 2 weeks would motivate patients to seek healthcare services, ${ }^{19}$ and the convenient and comprehensive FDCS could be one of the best choices. Unexpectedly, residents with chronic diseases showed lower willingness to maintain contracts with family doctors. It might be due to the shortage of medication for controlling chronic diseases in primary healthcare centers in China, ${ }^{20}$ which cannot meet health needs of patients with chronic diseases, and thus limited their willingness to maintain contracts. However, this effect was no longer significant in the mixed-effect regression analysis and multivariate logistic regression analyses. This finding might be related to the differences of socio-

Table 4 Stepwise Multivariate Logistic Regression Analysis on the Influencing Factors of Residents' Willingness to Maintain Contracts with Family Doctors in Eastern, Central, and Western China: 31 Provincial Administrative Regions, China, March to April 2019

\begin{tabular}{|c|c|c|c|c|c|c|c|}
\hline Variables & Characteristics & B & S.E. & Wald $\chi^{2}$ & $P$ & $\overline{\text { OR }}$ & $95 \% \mathrm{CI}$ \\
\hline \multicolumn{8}{|l|}{ Eastern China* } \\
\hline Rural/Urban (Ref.: Rural) & Urban & 0.298 & 0.083 & 12.716 & $<0.001$ & 1.347 & $1.143-1.586$ \\
\hline Household registration (Ref.: Immigrate) & Local & 0.226 & 0.093 & 5.870 & 0.015 & 1.254 & $1.044-1.506$ \\
\hline Medical insurance (Ref.: No insurance) & Having insurance & 0.439 & 0.162 & 7.318 & 0.007 & 1.551 & $1.128-2.131$ \\
\hline Self-rated health status (Ref.: Pretty poor) & Pretty good & 0.368 & 0.084 & 19.351 & $<0.001$ & 1.444 & $1.226-1.701$ \\
\hline Walking time to the nearest healthcare & $15-29$ & -0.228 & 0.090 & 6.449 & 0.011 & 0.796 & $0.667-0.949$ \\
\hline center $(\min )($ Ref.: $<15)$ & $\geq 30$ & -0.071 & 0.130 & 0.298 & 0.585 & 0.932 & $0.723-1.201$ \\
\hline Trust family doctors or not (Ref.: Distrust) & $\bar{T}$ rust & 1.452 & 0.091 & 252.688 & $<0.001$ & 4.272 & $3.571-5.109$ \\
\hline Satisfied with FDCS or not (Ref.: Unsatisfied) & Satisfied & 2.859 & 0.090 & 1005.827 & $<0.001$ & 17.449 & $14.623-20.822$ \\
\hline \multicolumn{8}{|l|}{ Central China ${ }^{\dagger}$} \\
\hline Walking time to the nearest healthcare center & $15-29$ & -0.473 & 0.160 & 8.793 & 0.003 & 0.623 & $0.456-0.852$ \\
\hline$(\min )($ Ref.: < 15) & $\geq 30$ & -0.522 & 0.221 & 5.583 & 0.018 & 0.593 & $0.385-0.915$ \\
\hline Trust family doctors or not (Ref.: Distrust) & Trust & 1.665 & 0.153 & 118.284 & $<0.001$ & 5.284 & $3.914-7.132$ \\
\hline Satisfied with FDCS or not (Ref.: Unsatisfied) & Satisfied & 3.177 & 0.151 & 441.251 & $<0.001$ & 23.966 & $17.819-32.235$ \\
\hline \multicolumn{8}{|l|}{ Western China } \\
\hline Trust family doctors or not (Ref.: Distr & Tru & 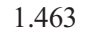 & 0.143 & 10 & $<0$. & 4.321 & $3.268-5.713$ \\
\hline Satisfied with FDCS or not (Ref.: Unsatisfied) & Satisfied & 2.874 & 0.144 & 397.162 & $<0.001$ & 17.714 & $13.352-23.501$ \\
\hline
\end{tabular}

Ref., reference; S.E., standard error; OR, odd ratios; CI, confidence index; LL, lower limit; UL, upper limit; min, minutes; FDCS, family doctor contract service

*Adjusted for age, gender, rural/urban, household registration status, economic status, medical insurances, self-rated health status, chronic disease, sick in last 2 weeks, alcohol consumption, physical exercise, walking time to nearest healthcare center, trust in family doctor or not, satisfied with family doctors or not

†Adjusted for age, gender, rural/urban, household registration status, economic status, self-rated health status, chronic disease, sick in last 2 weeks, alcohol consumption, walking time to nearest healthcare center, trust in family doctor or not, satisfied with family doctors or not

$\$$ Adjusted for gender, rural/urban, household registration status, economic status, self-rated health status, sick in last 2 weeks, walking time to nearest healthcare center, trust in family doctor or not, satisfied with family doctors or not 
demographic and health characteristics in residents with and without chronic diseases. More researches are needed to determine the association between chronic disease and willingness to maintain contracts with family doctors and to explore the potential reasons for this association. Residents with no alcohol consumption showed higher willingness than drinkers in this study. Individuals who do not drink alcohol are found to be more concerned about their own health. ${ }^{21}$ As "gatekeeper" of residents' health, ${ }^{22}$ family doctors may be welcomed by people practicing health-promoting behaviors.

Mixed-effect regression analysis showed that local registered residents had higher willingness to maintain contracts compared with migrants. This difference might be explained by Chinese household registration system, which is correlated with personal social welfare. ${ }^{23}$ Migrants, especially the rural-to-urban, are excluded from urban social and medical insurance systems and often live a marginalized life, which greatly reduces their opportunities to receive healthcare services from family doctors, let alone to maintain contracts. ${ }^{24}$ It is recommended that the government expand the FDCS to provide undifferentiated healthcare services to all permanent residents instead of only to local registered residents. Medical insurance was another influencing factor. In 2019, China's subsidies for medical insurances were no less than $520 \mathrm{RMB} /$ year for every citizen and the reimbursement rate was $60 \%{ }^{25} \mathrm{Ac}$ cordingly, enrolling in medical insurance could slash residents' out-of-pocket expenditure and reduce their economic burden from medical expenses, which would allow them to access better healthcare services. ${ }^{26}$ With these benefits, it makes sense that the covered residents showed higher willingness to maintain contracts with family physicians. Disparities in self-rated health status are attributed to different health-related factors. For example, a better self-rated health status is generally associated with the younger, the higher socioeconomic status, and high-quality social supports. ${ }^{27}$ Those have a worse self-rated health status generally report malnutrition, more social and economic burdens, and discrimination. ${ }^{28}$ All of these factors might directly or indirectly affect residents' willingness to maintain contracts with family doctors. Further, reporting bias also should be taken into account as patients might feel stigma, making them conceal their diseases and reporting a better health status. ${ }^{29}$ However, these participants were still inclined to maintain contracts to receive continuous healthcare. Similarly to previous studies, ${ }^{30}$ residents with walking time to the nearest healthcare centers $\leq 30 \mathrm{~min}$ showed higher willingness to maintain contracts than those with longer walking time. A shorter walking distance to healthcare centers means more convenient to get healthcare services, and requires less time cost or travel expenditure, encouraging residents to keep contracts with family doctors. At present, the accessibility of primary healthcare services in China varies greatly; it is especially poorer in areas with lower socio-economic status and in remote regions, making it inconvenient for residents there to visit family doctors and negatively affecting their willingness to maintain contracts. Therefore, it is suggested that policy makers establish preferential health policies and distribute more medical resources to these vulnerable areas. Finally, compared with residents who show distrust in their family doctors or low satisfaction with their healthcare services, willingness to maintain contracts among those trusting in or satisfied with family doctors increased by 3.403- and 17.514-fold, respectively, which are consistent with previous studies. ${ }^{31,32}$ Trust and satisfaction are subjective and direct indicators reflecting residents' actual feelings about their family doctors. It is not difficult to imagine that residents trusting in and satisfied with their family doctors were more inclined to maintain contracts.

For residents from Eastern, Central, and Western China, there were different influencing factors on their willingness to maintain contracts with family doctors. On one hand, the difference might be attributed to the substantial inequality in medical resources and healthcare levels in different regions. ${ }^{33}$ Up until 2018, there were 2.93 general practitioners per 10,000 population in Eastern China, compared with 1.73 and 1.66 in Central and Western regions. ${ }^{34}$ As the richer and higher-quality health resources are in Eastern China, residents there have more opportunities to access healthcare services. With the benefits of the FDCS, these residents might be more inclined to keep contracts. On the other hand, residents' health literacy could also have an effect on the difference. In 2019, the health literacy level of residents in Eastern China was $24.60 \%$, compared with $16.31 \%$ in Central China and $14.30 \%$ in Western China. ${ }^{35}$ These findings suggest that the government should provide policy support to Central and Western China to ensure the equal distribution of medical resources, including general practitioners and diagnosis and treatment technology, and to strengthen the quality and ability of their healthcare services. Furthermore, health educators need to give priority to improve residents' health literacy, especially those in Central and Western China, so as to arouse residents' interest in maintaining their own health and thus increase their willingness to maintain contracts with family doctors.

There are several strengths in this study. First, the study sheds new light on the evaluation of the quality of FDCS from the perspective of residents' willingness to maintain contracts with family doctors, which might produce targeted guidance for improving health policies relevant to FDCS. Second, we concluded some interesting findings, such as the different willingness to maintain contracts with family doctors between local and immigrate residents.

However, some limitations also should be noted. First, the cross-sectional design of this study limits its ability to identify the causal relationships between influencing factors and residents' willingness. Second, some other factors that might impact residents' willingness were not included in our survey, such as residents' psychological status and the publicity of 
FDCS in surrounding areas. Thus, more comprehensive and rigorous studies based on scientific sampling are needed. Third, since the proportion of participants aged 65 years and older was lower in this study, the implication of our findings for the elder population might be limited to some extent.

\section{CONCLUSIONS}

Residents' willingness to maintain contracts with family doctors might be an alternative evaluation indicator of the quality of FDCS. To increase resident's willingness, it is suggested to provide all residents, including migrants, the equal right to access healthcare services, through increasing the coverage of medical insurances, allocating more health resources in rural or remote areas, and enabling family doctors to fully play the "gatekeeper" role for the health of all residents.

Acknowledgments: We thank Dr. Shiyi Cao and Dr. Yanhong Gong for their professional guidance during the revision of the study. We also thank all participants in the survey and all staff members involved in this study for their hard work in data collection.

Corresponding Author: Zuxun Lu, Ph.D; Department of Social Medicine and Health Management, School of Public Health, Tongji Medical College, Huazhong University of Science and Technology, Wuhan, Hubei, China (e-mail: zuxunlu@yahoo.com).

Funding This study was supported by the National Social Science Foundation of China (Grant No. 18ZDA085). HJ was supported by the Australian National Health and Medical Research Council (GNT1141325) and Australian Research Council (DP200101781).

\section{Compliance with Ethical Standards:}

Before filling out the questionnaire, all participants provided informed consent on the first page of the questionnaire. This study was approved by the ethics committee of Tongji Medical College institutional review board, Huazhong University of Science and Technology, Wuhan, China.

Conflict of Interest: The authors declare that they do not have a conflict of interest.

\section{REFERENCES}

1. Shang X, Huang Y, Li B, et al. Residents' awareness of family doctor contract services, status of contract with a family doctor, and contract service needs in Zhejiang Province, China: a cross-sectional study. Int J Environ Res Public Health. 2019;16(18):3312.

2. National Health Commission of the People's Republic of China. The national experience promotion conference on deepening Medical Reform and China health development summit in 2017 released the typical experiences on deepening Medical Reform. 2017; http://www.nhc.gov. cn/tigs/ygjb/201708/997a76fd89814dlbaelc9b1229a91097.shtml. Accessed August 2, 2017.

3. Zhao Y, Lin J, Giu Y, et al. Demand and signing of general practitioner contract service among the urban elderly: a population-based analysis in Zhejiang Province, China. International journal of environmental research and public health. Mar 29 2017;14(4):356.

4. Yuan $\mathbf{X}$. National Health and Family Planning Commission: the family doctor contract service has covered 500 million people by November. 2017; http://www.xinhuanet.com/health/2017-12/16/c_1122120074. htm. Accessed December 16, 2017, 2017.
5. Medical Reform Office of State Council of the People's Republic of China. Notice on Printing and Distributing Guidance on Promoting Family Doctor Contracting Services. 2016. Available at: http://www.nhc.gov. cn/tigs/s3577/201606/e3e7d2670a8b4163b1fe8e409c7887af.shtml. Accessed March 1, 2020.

6. House J. UK National Health Service reforms mobilise doctors. Lancet (London, England). 2011;377(9768):797-800.

7. Bowman MA, Lucan SC, Rosenthal TC, Mainous AG, 3rd, James PA Family medicine research in the United States from the late 1960s into the future. Fam Med. 2017;49(4):289-295.

8. White B, Twiddy D. The state of family medicine: 2017. Fam Pract Manag. 2017;24(1):26-33.

9. Marcinowicz L, Jamiolkowski J, Gugnowski Z, Strandberg EL Fagerstrom C, Pawlikowska T. Evaluation of the Trust in Physician Scale (TIPS) of primary health care patients in north-east Poland: a preliminary study. Fam Med Prim Care Re. 2017;19(1):39-43.

10. Crooks VA, Li N, Snyder J, et al. "You don't want to lose that trust that you've built with this patient...": (dis)trust, medical tourism, and the Canadian family physician-patient relationship. BMC Fam Pract. 2015;16:25

11. Wang W, Haggerty J, Loban EK, Liu X. Evaluating primary health care performance from user perspective in China: review of survey instruments and implementation issues. Int $\mathrm{J}$ Environ Res Public Health. 2019; 16(6):926.

12. Valderas JM, Kotzeva A, Espallargues M, et al. The impact of measuring patient-reported outcomes in clinical practice: a systematic review of the literature. Qual Life Res. 2008;17(2):179-193.

13. Kersnik J. Determinants of customer satisfaction with the health care system, with the possibility to choose a personal physician and with a family doctor in a transition country. Health policy. 2001;57(2):155-164.

14. Welzel FD, Stein J, Hajek A, Konig HH, Riedel-Heller SG. Frequent attenders in late life in primary care: a systematic review of European studies. BMC Fam Pract. 2017;18(1):104.

15. Weinhold I, Gurtner S. Rural - urban differences in determinants of patient satisfaction with primary care. Soc Sci Med. 2018;212:76-85.

16. Kao AC, Jager AJ, Koenig BA, et al. Physician perception of pay fairness and its association with work satisfaction, intent to leave practice, and personal health. J Gen Intern Med. 2018;33(6):812-817.

17. National Health and Family Planning Commission of the People's Republic of China. China health statistical yearbook 2018. Beijing: Peking Union Medical College Publishing House; 2019.

18. He J, Chen $\mathbf{D}$, Tang $\mathbf{Z}$, et al. How the health institution combinative contracting mechanism influences community residents' patient experiences in Shanghai: A comparative study of data from two cross-sectional surveys. Int J Health Plann Manage. 2019;34(3):1036-1054.

19. Lu CH, Luo ZC, Wang JJ, Zhong JH, Wang PX. Health-related quality of life and health service utilization in Chinese rural-to-urban migrant workers. Int J Environ Res Public Health. 2015;12(2):2205-2214.

20. Su M, Zhang $\mathbf{Q}$, Bai X, et al. Availability, cost, and prescription patterns of antihypertensive medications in primary health care in China: a nationwide cross-sectional survey. Lancet (London, England) 2017; 390(10112):2559-2568.

21. Holmes J, Brown J, Meier P, Beard E, Michie S, Buykx P. Short-term effects of announcing revised lower risk national drinking guidelines on related awareness and knowledge: a trend analysis of monthly survey data in England. BMJ open. 2016;6(12):e013804.

22. Greenfield G, Foley $\mathbf{K}$, Majeed $\mathbf{A}$. Rethinking primary care's gatekeeper role. BMJ (Clinical research ed.). 2016;354:i4803.

23. Zheng $\mathbf{L}, \mathbf{H u} \mathbf{R}$, Dong $\mathbf{Z}$, Hao $\mathbf{Y}$. Comparing the needs and utilization of health services between urban residents and rural-to-urban migrants in China from 2012 to 2016. BMC Health Serv Res. 2018;18(1):717.

24. Huang $\mathbf{J}$, Liu $\mathbf{S}$, He R, et al. Factors associated with residents' contract behavior with family doctors in community health service centers: a longitudinal survey from China. PLoS One. 2018;13(11):e0208200.

25. National Healthcare Security Administration. Notice on Ensuring Basic Medical Security for Urban and Rural Residents in 2019. Available at: http://www.nhsa.gov.cn/art/2019/5/13/art_37_1286.html. Accessed Mar 1, 2020.

26. Sommers BD, Gawande AA, Baicker $\mathbf{K}$. Health insurance coverage and health - what the recent evidence tells us. N Engl J Med. 2017;377(6):586-593.

27. Salinero-Fort MA, Jimenez-Garcia R, del Otero-Sanz L, et al. Selfreported health status in primary health care: the influence of immigration and other associated factors. PLoS One. 2012;7(6):e38462.

28. Pumariega AJ, Rothe E, Pumariega JB. Mental health of immigrants and refugees. Community Ment Health J. 2005;41(5):581-597. 
29. Strkalj-Ivezic S. Stigma in clinical practice. Psychiatr Danub. 2013;25 Suppl 2:S200-202.

30. Wang X, Yang H, Duan Z, Pan J. Spatial accessibility of primary health care in China: a case study in Sichuan Province. Soc Sci Med. 2018;209:14-24.

31. Duckett J, Hunt $\mathbf{K}$, Munro N, Sutton M. Does distrust in providers affect health-care utilization in China? Health Policy Plan. 2016;31(8):1001-1009.

32. Robertson R, Dixon A, Le Grand J. Patient choice in general practice: the implications of patient satisfaction surveys. J Health Serv Res Policy. 2008; 13(2):67-72

33. Wang M, Fang H, Bishwajit G, Xiang Y, Fu H, Feng Z. Evaluation of rural primary health care in Western China: a cross-sectional study. Int $\mathrm{J}$ Environ Res Public Health. 2015;12(11):13843-13860.
34. National Health Commission of People's Republic of China. China Health Statistics Yearbook (2019). Beijing: Peking Union Medical College Press; 2019.

35. Press and Publicity Department, National Health Commission of the People's Republic of China. Up to 2019, the national health literacy level in China has risen to $19.17 \%$. 2020; http://www.nhc.gov.cn/xcs/s3582/ 202004/df8d7c746e664ad783d1c1cf5ce849d5.shtml. Accessed 25 April, 2020, 2020.

Publisher's Note Springer Nature remains neutral with regard to jurisdictional claims in published maps and institutional affiliations. 